\title{
Effectiveness of meditative movement on COPD: a systematic review and meta-analysis
}

This article was published in the following Dove Press journal:

International Journal of COPD

\section{Lu-Ling $\mathrm{Wu}^{\prime}$ \\ Zheng-Kun Lin $^{2}$ \\ Hui-Dan Weng ${ }^{3}$ \\ Qiao-Fang $\mathrm{Qi}^{4}$ \\ Jun $\mathrm{Lu}^{5}$ \\ Kai-Xiong Liu ${ }^{6}$}

'Department of Respiratory

Medicine, Fuzhou Pulmonary Hospital,

Fuzhou, People's Republic of China;

${ }^{2}$ Department of Rehabilitation,

No. 175 Hospital of PLA, Zhangzhou,

Fujian, People's Republic of China;

${ }^{3}$ Postgraduate Institute of Fujian

Medical University, Fuzhou, People's

Republic of China; ${ }^{4}$ Department

of Respiratory Medicine, Fuzhou

Pulmonary Hospital, Fuzhou, People's

Republic of China; ${ }^{5}$ Department of

Medical Oncology, Fuzhou Pulmonary

Hospital, Fuzhou, People's Republic

of China; ${ }^{6}$ Department of Respiratory

Medicine, The First Affiliated Hospital,

Fujian Medical University, Fuzhou,

People's Republic of China
Correspondence: Kai-Xiong Liu Department of Respiratory Medicine, The First Affiliated Hospital, Fujian Medical University, 20 Chazhong Road, Fuzhou 350005, People's Republic of China

Email Ikxfpt@I63.com

\begin{abstract}
Background: The effectiveness of meditative movement (tai chi, yoga, and qigong) on COPD remained unclear. We undertook a systematic review and meta-analysis to determine the effectiveness of meditative movement on COPD patients.

Methods: We searched PubMed, Web of Science, EMBASE, and the Cochrane Center Register of Controlled Trials for relevant studies. The methods of standard meta-analysis were utilized for identifying relevant researches (until August 2017), quality appraisal, and synthesis. The primary outcomes were the 6-minute walking distance (6MWD), lung function, and dyspnea levels.

Results: Sixteen studies involving 1,176 COPD patients were included. When comparing with the control group, the 6MWD was significantly enhanced in the treatment group (3 months: mean difference $[\mathrm{MD}]=25.40 \mathrm{~m}, 95 \% \mathrm{CI}$ : 16.25 to 34.54 ; 6 months: $\mathrm{MD}=35.75 \mathrm{~m}, 95 \% \mathrm{CI}$ : 22.23 to 49.27$)$, as well as functions on forced expiratory volume in $1 \mathrm{~s}\left(\mathrm{FEV}_{1}\right)$ (3 months: $\mathrm{MD}=0.1 \mathrm{~L}, 95 \% \mathrm{CI}: 0.02$ to $0.18 ; 6$ months: $\mathrm{MD}=0.18 \mathrm{~L}, 95 \% \mathrm{CI}: 0.1$ to 0.26 ), and $\mathrm{FEV}_{1} \%$ predicted ( 3 months: $4 \mathrm{~L}, 95 \%$ CI: 2.7 to $5.31 ; 6$ months: $\mathrm{MD}=4.8 \mathrm{~L}, 95 \%$ CI: 2.56 to 7.07 ). Quality of life for the group doing meditative movement was better than the control group based on the Chronic Respiratory Disease Questionnaire dyspnea score (MD $=0.9$ units, $95 \%$ CI: 0.51 to 1.29 ) and fatigue score ( $\mathrm{MD}=0.75$ units, $95 \%$ CI: 0.42 to 1.09 ) and the total score (MD=1.92 units, $95 \%$ CI: 0.54 to 3.31 ).
\end{abstract}

Conclusion: Meditative movement may have the potential to enhance lung function and physical activity in COPD patients. More large-scale, well-designed, multicenter, randomized controlled trials should be launched to evaluate the long-range effects of meditative movement.

Keywords: meditative movement, COPD, meta-analysis, tai chi, yoga, qigong

\section{Introduction}

COPD is characterized by nonreversible airflow obstruction and intermittent exacerbations. It was a major cause of morbidity and mortality worldwide. ${ }^{1-4}$ Despite progress in pharmacologic and surgical treatments, many patients continue to suffer from dyspnea and substantial limitations in daily activities. They are often trapped in a vicious cycle of inactivity, initiated by breathlessness. ${ }^{5,6}$ Rehabilitation may alleviate the symptoms, impede the deterioration of lung functions, and improve health-related quality of life among (HRQoL) COPD patients. More and more experts are beginning to realize the importance of pulmonary rehabilitation for COPD patients. Exercise training should be one of the vital approaches in the treatment of COPD. ${ }^{7,8}$

Meditative movement is proposed as a gentle exercise training and incorporates meditation, breathing, and relaxation. ${ }^{9}$ Meditative movement, including forms such 
as tai chi, yoga, and qigong, incorporates: focus on the mind; movements, usually slow, relaxed, flowing and choreographed; a focus on breathing, and a deep and calm state of physical and mental relaxation. ${ }^{9}$ tai chi is a centuries-old Chinese health practice. It involves a series of movements performed in a slow, well-balanced and focused manner, and is accompanied by deep breathing. Qigong is also an ancient Chinese exercise that include meditation, physical movement, relaxation, and breathing exercises to restore and maintain balance. Qigong is designed to control the vital energy (qi) of the body along the energy channels (meridians). Qigong combined with tai chi may keep the body, mind, and spirit in a state of alignment and balance. ${ }^{10}$ Yoga originated from ancient India, and consisted of pranayama, sithali, kapalabhati, asanas, and meditation. The exercises may coordinate the individual self with the transcendental self. ${ }^{11}$

Although some studies have reported that meditative movements exerted beneficial effects on COPD patients, ${ }^{12,13}$ its definite effectiveness remains unclear. Hence, we performed a systematic review and meta-analysis to evaluate the effectiveness of meditative movement as complementary therapy for COPD patients.

\section{Methods}

\section{Search strategy and study selection criteria} The following databases were searched: PubMed, EMBASE, Web of Science, and the Cochrane Center Register of Controlled Trials. No language restrictions were imposed. Search terms included: (Tai Chi or Taiji OR Tai Chi Chuan OR Qigong OR Qi Gong OR Chi Kung OR traditional Chinese exercise or yoga or meditative movement) AND (chronic obstructive pulmonary disease OR COPD OR chronic obstructive lung disease OR chronic obstructive airway disease OR emphysema OR chronic airflow limitation OR chronic airway obstruction). Studies were eligible for inclusion in this review if they met the following criteria: 1) were randomized controlled trials (RCTs); 2) used exercises training such as tai chi or qigong or tai chi combined with qigong or yoga as intervention in the experimental group; 3) included COPD patients according to the Global Initiative for Chronic Obstructive Lung Disease criteria; 4) used nonexercise in control groups or other physical exercise training in comparison groups.

\section{Data extraction}

Two reviewers (LLW and KXL) independently screened studies for inclusion, retrieved potentially relevant studies, and determined study eligibility. Any discrepancies were resolved by the way of consensus. The extracted information included the following: 1) the details of publication (the first author's last name, year of publication); 2) characteristics of participants in the study (the sample size, age, and severity of disease); 3) interventions (eg, the form of intervention, exercise time, the duration and frequency of training); 4) outcome measures.

\section{Outcome measures}

The primary outcomes were 6-minute walking distance (6MWD), lung function (forced expiratory volume in $1 \mathrm{~s}$ $\left[\mathrm{FEV}_{1}\right]$ and forced vital capacity [FVC]), dyspnea, and fatigue levels. The secondary outcomes were arterial blood gas tensions $\left(\mathrm{PaCO}_{2}, \mathrm{PaO}_{2}\right)$ and scores from quality of life questionnaires. We categorized outcomes as short-term (1-3 months) and mid-term ( 6 months) follow-up. The outcomes that could not be pooled in the meta-analysis are listed in Table 1.

\section{Quality assessment}

We used the Cochrane risk of bias assessment tool. ${ }^{14} \mathrm{~A}$ low value, unclear or high-risk bias was assigned in the following domains: generation in random sequence, allocation concealment, blinding methods, incomplete data among the outcome data, selective reporting, and other biases. Two reviewers (LLW and KXL) independently appraised the quality of the included trials. Any discrepancies were resolved by consensus in the presence of a third investigator.

\section{Statistical analysis}

We undertook statistical analysis by using Cochrane systematic review software Review Manager (RevMan; Version 5.3.5). Eligible studies were analyzed using the mean and SDs to measure the change from baseline to endpoint in each intervention period. Since all outcomes were continuous variables, mean difference (MD) with 95\% CIs were calculated when studies reported their results of the same variables measured with the same units of measure. $I^{2}$ statistic was used to assess the heterogeneity. And random effect models were used to address variations in studies. ${ }^{15}$ Meanwhile, $I^{2}$ values were classified as low $(0 \%$ to $<25 \%)$, medium $(25 \%$ to $<75 \%)$, and high $(\geq 75 \%)$. ${ }^{16}$ The results were displayed as Forest plots.

\section{Results}

We retrieved a total of 1,145 references. Sixteen studies finally fulfilled the inclusion criteria and were further analyzed. ${ }^{36-51}$ A flow chart for the studies evaluated and the reasons for exclusion is shown in Figure 1. Of the included 
Table I Characteristics of included studies

\begin{tabular}{|c|c|c|c|c|c|c|c|c|}
\hline $\begin{array}{l}\text { Author, } \\
\text { year }\end{array}$ & Country & $\begin{array}{l}\text { Comparison } \\
\text { arms }\end{array}$ & $\begin{array}{l}\text { Sample } \\
\text { size, } \mathbf{N}\end{array}$ & Protocol & $\begin{array}{l}\text { Mean age in } \\
\text { years (SD/ } \\
\text { range) }\end{array}$ & $\begin{array}{l}\text { FEV } \\
\text { predicted (\%) }\end{array}$ & Duration & Outcomes \\
\hline Chan & Hong & GI: TCQ & GI: 70 & GI: 60 minutes/session & GI: 71.7 (8.2) & GI: 50.1 (2I.8) & 6 months & I. 6MWD \\
\hline et $\mathrm{al}^{36}$ & Kong, & G2: Exercise & G2: 69 & 2 sessions/week & G2: $73.6(7.5)$ & G2: $56.4(25.6)$ & & 2. $\mathrm{FEV}_{1}, \mathrm{FVC}$ \\
\hline 2013 & China & G3: Control & G3: 67 & $\begin{array}{l}3 \text { months } \\
\text { G2: } 60 \text { minutes/day } \\
3 \text { months }\end{array}$ & G3: $73.6(7.4)$ & G3: 55.1 (23.3) & & $\begin{array}{l}\text { 3. } \mathrm{Borg} \\
\text { 4. } \mathrm{SaO} 2 \%\end{array}$ \\
\hline Chan & Hong & GI: TCQ & GI: 70 & GI: 60 minutes/session & GI: 71.7 (8.2) & GI: 50.1 (2I.8) & 6 months & SGQR \\
\hline et $\mathrm{al},{ }^{37}$ & Kong, & G2: Exercise & G2: 69 & 2 sessions/week & G2: $73.6(7.5)$ & G2: $56.4(25.6)$ & & \\
\hline 2013 & China & G3: Control & G3: 67 & $\begin{array}{l}3 \text { months } \\
\mathrm{G} 2: 60 \text { minutes/day } \\
3 \text { months }\end{array}$ & G3: $73.6(7.4)$ & G3: 55.1 (23.3) & & \\
\hline $\begin{array}{l}\text { Zhang } \\
\text { et } \mathrm{al}^{38} \\
2016\end{array}$ & $\begin{array}{l}\text { Jiangsu, } \\
\text { China }\end{array}$ & $\begin{array}{l}\text { GI: QYJJ } \\
\text { G2: Exercise } \\
\text { G3: Control }\end{array}$ & $\begin{array}{l}\text { GI: } 42 \\
\text { G2: } 43 \\
\text { G3: } 45\end{array}$ & $\begin{array}{l}\text { GI: } 60 \text { minutes/day } \\
7 \text { sessions/week } \\
6 \text { months } \\
\text { G2: } 60 \text { minutes/day } \\
6 \text { months }\end{array}$ & $\begin{array}{l}\text { GI: } 64.77(11.07) \\
\text { G2: } 63.34(7.86) \\
\text { G3: } 62.35(9.27)\end{array}$ & $\begin{array}{l}\text { GI: } 59.12(4.13) \\
\text { G2: } 57.39(5.37) \\
\text { G3: } 58.11(4.37)\end{array}$ & 6 months & $\begin{array}{l}\text { I. } 6 \mathrm{MWD} \\
\text { 2. } \mathrm{FEV}, \mathrm{FEV}, \% \text {, } \\
\text { FEV, } / F V C \\
\text { 3. CAT }\end{array}$ \\
\hline $\begin{array}{l}\text { Xiao and } \\
\text { Zhuang, } \\
2015\end{array}$ & $\begin{array}{l}\text { Beijing, } \\
\text { China }\end{array}$ & $\begin{array}{l}\text { GI: LQG } \\
\text { G2: Exercise }\end{array}$ & $\begin{array}{l}\text { GI: } 63 \\
\text { G2: } 63\end{array}$ & $\begin{array}{l}\text { GI: } 45 \text { minutes/session } \\
4 \text { sessions/week } \\
30 \text { minutes walking/day } \\
6 \text { months } \\
\text { G2: } 30 \text { minutes/day } \\
6 \text { months }\end{array}$ & $\begin{array}{l}\text { GI: } 72.2(I .7) \\
\text { G2: } 70.9(1.4)\end{array}$ & $\begin{array}{l}\text { GI: } 4 \text { I.5 (4.5) } \\
\text { G2: } 40.7(4.0)\end{array}$ & 6 months & $\begin{array}{l}\text { I. } 6 \mathrm{MWD} \\
\text { 2. CRQ, SF-36 }\end{array}$ \\
\hline $\begin{array}{l}\mathrm{Ng} \text { et al, }{ }^{40} \\
201 \mathrm{I}\end{array}$ & $\begin{array}{l}\text { Hong } \\
\text { Kong, } \\
\text { China }\end{array}$ & $\begin{array}{l}\text { GI: QG } \\
\text { G2: Exercise }\end{array}$ & $\begin{array}{l}\text { GI: } 40 \\
\text { G2: } 40\end{array}$ & $\begin{array}{l}\text { GI: } 45 \text { minutes/session } \\
4 \text { sessions/week } \\
6 \text { months } \\
\text { G2: } 30 \text { minutes/day } \\
6 \text { months }\end{array}$ & $\begin{array}{l}\text { GI: } 71.75(1.05) \\
G 2: 73.12(1.33)\end{array}$ & $\begin{array}{l}\text { GI: } 37.13(2.22) \\
G 2: 36.75(2.11)\end{array}$ & 6 months & $\begin{array}{l}\text { I. } 6 M W D \\
\text { 2. CRQ, SF-36 }\end{array}$ \\
\hline $\begin{array}{l}\text { Yeh } \\
\text { et al, }{ }^{41} \\
2010\end{array}$ & USA & $\begin{array}{l}\text { GI: TC } \\
\text { G2: Control }\end{array}$ & $\begin{array}{l}\text { GI: } 5 \\
\text { G2: } 5\end{array}$ & $\begin{array}{l}\text { GI: } 60 \text { minutes/session } \\
2 \text { sessions/week } \\
3 \text { months }\end{array}$ & $\begin{array}{l}\text { GI: } 65(6) \\
\text { G2: } 66(6)\end{array}$ & $\begin{array}{l}\text { GI: } 53(7) \\
\text { G2: } 47(7)\end{array}$ & 3 months & $\begin{array}{l}\text { 1. } 6 M W D \\
\text { 2. } F E V_{1} / F V C \\
\text { 3. CRQ }\end{array}$ \\
\hline $\begin{array}{l}\text { Leung } \\
\text { et al, }{ }^{42} \\
2013\end{array}$ & Australia & $\begin{array}{l}\text { GI: TC } \\
\text { G2: Control }\end{array}$ & $\begin{array}{l}\text { GI: } 22 \\
\text { G2: } 20\end{array}$ & $\begin{array}{l}\text { GI: } 60 \text { minutes/day } \\
7 \text { days/week } \\
3 \text { months }\end{array}$ & $73(8)$ & $59(16)$ & 3 months & I. CRQ \\
\hline $\begin{array}{l}\text { Niu } \\
\text { et al, }{ }^{43} \\
2014\end{array}$ & $\begin{array}{l}\text { Changsha, } \\
\text { China }\end{array}$ & $\begin{array}{l}\text { GI: TC } \\
\text { G2: Control }\end{array}$ & $\begin{array}{l}\text { GI: } 20 \\
\text { G2: } 20\end{array}$ & $\begin{array}{l}\text { GI: } 50 \text { minutes/session } \\
\text { I days/session } \\
7 \text { sessions/week } \\
6 \text { months }\end{array}$ & $\begin{array}{l}\text { GI: } 59.7(2.76) \\
\text { G2: } 61.3(2.89)\end{array}$ & $\begin{array}{l}\text { GI: } 41.9(5.50) \\
\text { G2: } 43.7(5.16)\end{array}$ & 6 months & $\begin{array}{l}\text { I. } 6 \mathrm{MWD} \\
\text { 2. } \mathrm{FEV}_{1}, \mathrm{FEV}_{1} \% \\
\text { 3. } \mathrm{PaO}_{2}, \mathrm{PaCO}_{2}\end{array}$ \\
\hline $\mathrm{Ng}$ et $\mathrm{al},{ }^{44}$ & Hong & GI: TC & GI: 94 & GI: 60 minutes/session & GI: 74.16 (6.46) & GI: $56.4(23.8 I)$ & 6 months & I. 6MWD \\
\hline 2014 & $\begin{array}{l}\text { Kong, } \\
\text { China }\end{array}$ & G2: Control & G2: 98 & $\begin{array}{l}7 \text { sessions/week } \\
6 \text { weeks }\end{array}$ & G2: $74.13(6.8 I)$ & G2: $63.1(22.12)$ & & $\begin{array}{l}\text { 2. } \mathrm{FVC}, \mathrm{FEV}_{1} \text {, } \\
\mathrm{FEV}, \% \\
\text { 3. } \mathrm{SGRQ} \\
\text { 4. } \mathrm{SaO}_{2}\end{array}$ \\
\hline $\begin{array}{l}\text { Ranjita } \\
\text { et al, }{ }^{45} \\
2016\end{array}$ & India & $\begin{array}{l}\text { GI: Yoga } \\
\text { G2: Control }\end{array}$ & $\begin{array}{l}\text { GI: } 36 \\
\text { G2: } 36\end{array}$ & $\begin{array}{l}\text { GI: } 90 \text { minutes/session } \\
6 \text { sessions/week } \\
3 \text { months }\end{array}$ & $\begin{array}{l}\text { GI: } 53.69(5.66) \\
G 2: 54.4 I(5.40)\end{array}$ & NA & 3 months & $\begin{array}{l}\text { I. } 6 \mathrm{MWD} \\
\text { 2. Brog } \\
\text { 3. } \mathrm{SpO} 2 \%\end{array}$ \\
\hline $\begin{array}{l}\text { Gupta } \\
\text { et al, } 46 \\
2014\end{array}$ & India & $\begin{array}{l}\text { GI: Yoga } \\
\text { G2: Control }\end{array}$ & $\begin{array}{l}\text { GI: } 25 \\
\text { G2: } 25\end{array}$ & $\begin{array}{l}\text { GI: } 30 \text { minutes/session } \\
2 \text { sessions/week } \\
3 \text { months }\end{array}$ & $\begin{array}{l}\text { GI: } 52.5(3.9) \\
\text { G2: } 52(4.1)\end{array}$ & $\begin{array}{l}\text { GI: } 5 \text { I.I (8.7) } \\
\text { G2: } 49.6(8.6)\end{array}$ & 3 months & $\begin{array}{l}\text { I. } 6 \mathrm{MWD} \\
\text { 2. } \mathrm{FEV}_{1} \% \\
\text { 3. CAT }\end{array}$ \\
\hline Donesky- & USA & GI: Yoga & GI: 14 & GI: 60 minutes/session & GI: 72.2 (6.5) & GI: $51.2(10.5)$ & 3 months & I. 6MWD \\
\hline $\begin{array}{l}\text { Cuenco } \\
\text { et al, }{ }^{47} \\
2009\end{array}$ & & G2: Control & G2: 15 & $\begin{array}{l}2 \text { sessions/week } \\
3 \text { months }\end{array}$ & G2: 67.7 (II.5) & G2: 44.4 (19.0) & & $\begin{array}{l}\text { 2. } \mathrm{FEV}_{1} / \mathrm{FVC} \text {, } \\
\mathrm{FEV}_{1} \% \\
\text { 3. CRQ, SF-36 }\end{array}$ \\
\hline $\begin{array}{l}\text { Soni } \\
\text { et } \mathrm{al}^{48} \\
2012\end{array}$ & India & $\begin{array}{l}\text { GI: Yoga } \\
\text { G2: Control }\end{array}$ & $\begin{array}{l}\text { GI: } 30 \\
\text { G2: } 30\end{array}$ & $\begin{array}{l}\text { GI: } 45 \text { minutes/day } \\
2 \text { months }\end{array}$ & $45(7.65)$ & NA & 2 months & I. TLCO \\
\hline
\end{tabular}


Table I (Continued)

\begin{tabular}{|c|c|c|c|c|c|c|c|c|}
\hline $\begin{array}{l}\text { Author, } \\
\text { year }\end{array}$ & Country & $\begin{array}{l}\text { Comparison } \\
\text { arms }\end{array}$ & $\begin{array}{l}\text { Sample } \\
\text { size, } \mathbf{N}\end{array}$ & Protocol & $\begin{array}{l}\text { Mean age in } \\
\text { years (SD/ } \\
\text { range) }\end{array}$ & $\begin{array}{l}\text { FEV } \\
\text { predicted (\%) }\end{array}$ & Duration & Outcomes \\
\hline Tandon, ${ }^{49}$ & Australia & GI: Yoga & GI: 12 & GI: 60 minutes/session & GI: 59 (3.06) & NA & 9 months & I. $\mathrm{FEV}_{1}, \mathrm{FVC}$ \\
\hline 1978 & & G2: Control & G2: 12 & $\begin{array}{l}\text { I-4 weeks: } 3 \text { sessions/ } \\
\text { week } \\
\text { 5-8 weeks: } 2 \text { sessions/ } \\
\text { week } \\
9 \text { weeks }-9 \text { months: } \\
2 \text { sessions/week } \\
9 \text { months }\end{array}$ & G2: 58 (3.06) & & & 2. $\mathrm{PaO}_{2}, \mathrm{PaCO}_{2}$ \\
\hline Kulpati & India & GI: Yoga & GI: 25 & GI: 30 minutes/session & GI: 50.6 (I2.23) & NA & 3 months & I. FEV , FVC, \\
\hline et $a,^{51}$ & & G2: Control & G2: 50 & 2 sessions/week & G2: $48.65(9.17)$ & & & $\mathrm{FEV}_{1} / \mathrm{FVC}$ \\
\hline 1982 & & & & 3 months & & & & 2. $\mathrm{PaO}_{2}, \mathrm{PaCO}_{2}$ \\
\hline Katiyar & India & & GI: Yoga & GI: 30 minutes/session & GI: 53.3 (2.9) & GI: 48 (2.4) & 3 months & I. $\mathrm{FEV}_{1}, \mathrm{FVC}$ \\
\hline and & & & G2: & 6 sessions/week & G2: 5 I.I (3) & G2: $48(2)$ & & 2. SGRQ \\
\hline Bihari, ${ }^{50}$ & & & Control & 3 months & & & & \\
\hline 2006 & & & & & & & & \\
\hline
\end{tabular}

Abbreviations: 6MWD, 6-minute walking distance; CAT, exercise of the COPD Assessment Test; CRQ, Chronic Respiratory Disease Questionnaire; FEV, forced expiratory volume in I s; FEV \% predicted, FEV, percent predicted normal values; FVC, forced vital capacity; FEV /FVC, the ratio of FEV, to FVC; G, Group; LQG, Liuzijue qigong; NA, not available; $\mathrm{PaCO}_{2}$, partial pressure of carbon dioxide; $\mathrm{PaO}_{2}$, partial pressure of oxygen; QG,Qigong; QYJJ, Qigong Yi Jinjing; SF-36, 36-Item Short Form Health Survey; SGRQ, St George Respiratory Questionnaire; TC, Tai chi; TCQ, Tai chi Qigong; Borg, Borg scale of dyspnea and fatigue levels; TLCO, transfer factor of lung for carbon monoxide.

studies, 7 evaluated yoga, 4 tai chi, 3 qigong, and 2 tai chi and qigong combined. Yoga, tai chi, and qigong were included. The exercise group used breathing and walking as a physical exercise. Breathing exercises comprised pursed-lip breathing and diaphragmatic breathing.

\section{Settings}

Five of these 15 studies was conducted in India (Ranjita 2015; Gupta 2014; Soni 2012; Kulpati 1982; Katiyar 2006), 2 in

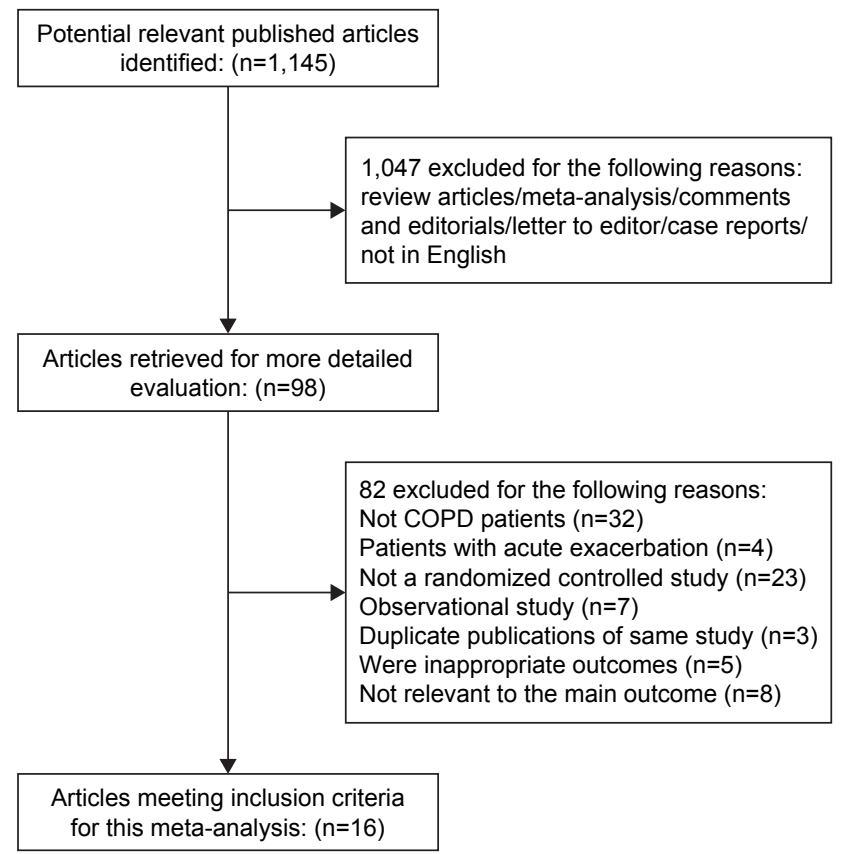

Figure I Flow of study selection. the USA (Yeh 2010; Donesky-Cuenco 2009), 2 in Australia (Leung 2013; Tandon 1978), 3 in Hong Kong (Chan 2010; $\mathrm{Ng} 2011 ; \mathrm{Ng} 2014)$, and the rest in other provinces in China (Zhang 2015; Xiao 2015; Niu 2014). Most studies were conducted in outpatient clinics and published between 1975 and 2015.

\section{Study characteristics}

A total of 1,176 COPD patients were included in the current study. The sizes of sample, according to statistics, ranged from 10 to 206. The patients were recruited from outpatients or health care centers. Studies were conducted in a diverse array of countries, mostly in Southeast Asia. Characteristics of the included studies were summarized in Table 1. Four articles written by Chan et al ${ }^{12,53}$ derived from the same study. Since the research by Chan et al had a patient population that appeared to be described in recent studies ${ }^{36,37}$ of different study design, we decided to exclude the previous 2. ${ }^{52,53}$ All studies were published between 1990 and 2017, and the duration ranged from 12 weeks to 9 months. Most of the trials used tai chi or yoga as the experimental intervention; furthermore, 3 trials used qigong ${ }^{38-40}$ and 2 trials $^{36,37}$ used tai chi combined with qigong. All the included trials described the details involving the duration, frequencies, and session length of the interventions. The mean age ranged from 45 to 74.1 years, and the mean baseline lung function varied from $36.75 \%$ to $59.12 \%$ predicted $\mathrm{FEV}_{1}$. Disease severity ranged from mild to very severe, as reported by study authors. Five studies $^{36-38,42,44}$ recruited participants with disease severity 
ranging from mild to moderate; $7^{39-41,43,46,47,51}$ from moderate to severe; and $4^{45,48-50}$ studies did not specify the level of severity included but provided the mean value of $\%$ predicted $\mathrm{FEV}_{1}$ and $\mathrm{SD}$ within the range of mild-to-severe COPD. The frequencies of training ranged from 2 to 7 sessions each week, and the time of exercise lasted 30-90 minutes per session; most common was 30-60 minutes. Yoga tended to be practised for longer and more frequently than tai chi or qigong. One trial ${ }^{48}$ measured the outcomes of 2 months, 7 trials $^{41,42,45-47,50,51}$ measured the outcomes for 3 months, 7 trials $^{36-40,43,44}$ measured the outcomes for 6 months, and 1 trial $^{49}$ measured the outcomes of 9 months. The interventions in control groups were education, breathing technique, and walking combined with or without breathing technique. All participants received the usual medical treatment in addition to the experimental intervention.

\section{Risk of bias of studies}

The assessment of the included studies are shown in Table 2, which displayed ${ }^{36-51}$ the risk of bias. Four trials, ${ }^{40-42,44}$ according to the recommended criteria of the Cochrane Handbook, were judged to be in low risk in bias; 10 trials $^{36,38,39,43,45-49,51}$ were judged to be in unclear risk of bias, and 1 trial $^{50}$ was judged to be in high risk of bias as shown in Figure 2.

\section{Outcomes 6MWD}

\section{Meditative movement versus nonexercise}

The 6MWD was significantly enhanced in the experimental group (MD $25.40 \mathrm{~m}, 95 \% \mathrm{CI}: 16.25$ to $34.54, P<0.00001$ ) compared with the nonexercise group at the third month in a pooled analysis of 8 studies $(n=644) .{ }^{36,38,41,44-47,51}$ These trials showed heterogeneity when they were pooled in a meta-analysis $\left(P\right.$ for heterogeneity $=0.002, I^{2}=68 \%$ ). Four RCTs $(n=455)^{36,38,43,44}$ provided information regarding $6 \mathrm{MWD}$ at the sixth month. Pooled analysis showed that experimental group was associated with a statistically significant improvement in 6MWD (MD 35.75 m, 95\% CI: 22.23 to $49.27, P<0.00001)$ using a random-effects model. The results of the heterogeneity test was not significant $(P$ for heterogeneity $=0.009, I^{2}=74 \%$; Figure $\left.3 \mathrm{~A}\right)$. The $6 \mathrm{MWD}$ effect size of 1 trial $^{46}$ was obviously lower than the other trials; furthermore, if this study was excluded, heterogeneity was markedly abated. Thus, a subgroup analysis was undertaken according to the different Style Meditative movement in the intervention.

\section{Meditative movement versus walking exercise}

Two studies, ${ }^{36,38}$ involving 224 participants, estimated changes in functional capacity using the 6-minute walk test at the third month. The combined MD from 2 studies $(\mathrm{n}=224)$ was $15.53 \mathrm{~m}$ (95\% CI: 11.59 to $19.48, P$-value $<0.00001)$. We detected no subgroup differences between experimental group and the exercise group $\left(P\right.$-value $\left.=0.33, I^{2}=0 \%\right)$. Four trials $^{36,38-40}(n=430)$ estimated the effects of 6MWD on the experimental group and compared with walking exercise at 6 months. It reported that the experimental group showed an improvement in 6MWD compared with exercise group, but the difference was not significant (MD 19.36 m, 95\% CI: 9.0

Table 2 Assessment of included studies for risk of bias

\begin{tabular}{|c|c|c|c|c|c|c|c|c|}
\hline Author, year & $\begin{array}{l}\text { Adequate } \\
\text { sequence } \\
\text { generation }\end{array}$ & $\begin{array}{l}\text { Allocation } \\
\text { concealment }\end{array}$ & $\begin{array}{l}\text { Blinding of } \\
\text { participants } \\
\text { and } \\
\text { personnel }\end{array}$ & $\begin{array}{l}\text { Blinding of } \\
\text { outcome } \\
\text { assessment }\end{array}$ & $\begin{array}{l}\text { Incomplete } \\
\text { outcome } \\
\text { data }\end{array}$ & $\begin{array}{l}\text { Selective } \\
\text { reporting }\end{array}$ & $\begin{array}{l}\text { Other } \\
\text { bias }\end{array}$ & Study design \\
\hline Chan et al, ${ }^{36,37} 2013$ & Low & Unclear & Unclear & Low & Low & Low & Unclear & RCT (single-blind) \\
\hline Zhang et al,, 2016 & Unclear & Unclear & Low & Unclear & Unclear & Low & Unclear & RCT (single-blind) \\
\hline Xiao and Zhuang, ${ }^{39} 2015$ & Unclear & Unclear & Low & Low & Low & Low & Unclear & RCT (single-blind) \\
\hline $\mathrm{Ng}$ et al, ${ }^{40} 20 \mathrm{II}$ & Low & Low & Low & Low & Low & Low & Unclear & RCT (single-blind) \\
\hline Yeh et al, ${ }^{4 l} 2010$ & Low & Low & Low & Low & Low & Low & Unclear & RCT (single-blind) \\
\hline Leung et al, ${ }^{42} 2013$ & Low & Low & Low & Low & Low & Low & Unclear & RCT (single-blind) \\
\hline Niu et al, ${ }^{43} 2014$ & Low & Unclear & Unclear & Low & Low & Low & Unclear & RCT (single-blind) \\
\hline $\mathrm{Ng}$ et al, ${ }^{44} 2014$ & Low & Low & Low & Low & Low & Low & Unclear & RCT (single-blind) \\
\hline Ranjita et al, ${ }^{45} 2016$ & Unclear & Unclear & Low & Low & Low & Low & Unclear & RCT (single-blind) \\
\hline Gupta et al, ${ }^{46} 2014$ & Unclear & Unclear & Low & Low & Unclear & Low & Unclear & $\mathrm{RCT}$ \\
\hline $\begin{array}{l}\text { Donesky-Cuenco et al, }{ }^{47} \\
2009\end{array}$ & Unclear & Unclear & Low & Low & Unclear & Low & Unclear & $\mathrm{RCT}$ \\
\hline Soni et al, ${ }^{48} 2012$ & Unclear & Unclear & Unclear & Unclear & Low & Low & Unclear & $\mathrm{RCT}$ \\
\hline Tandon, ${ }^{49} 1978$ & Unclear & Unclear & Unclear & Unclear & Low & Low & Unclear & $\mathrm{RCT}$ \\
\hline Kulpati et al, ${ }^{51} 1982$ & Unclear & Unclear & Unclear & Unclear & Unclear & Low & Unclear & $\mathrm{RCT}$ \\
\hline $\begin{array}{l}\text { Katiyar and Bihari, }{ }^{50} \\
2006\end{array}$ & Low & Unclear & Unclear & Low & Low & Low & Unclear & $\mathrm{RCT}$ \\
\hline
\end{tabular}

Abbreviation: RCT, randomized controlled trial. 


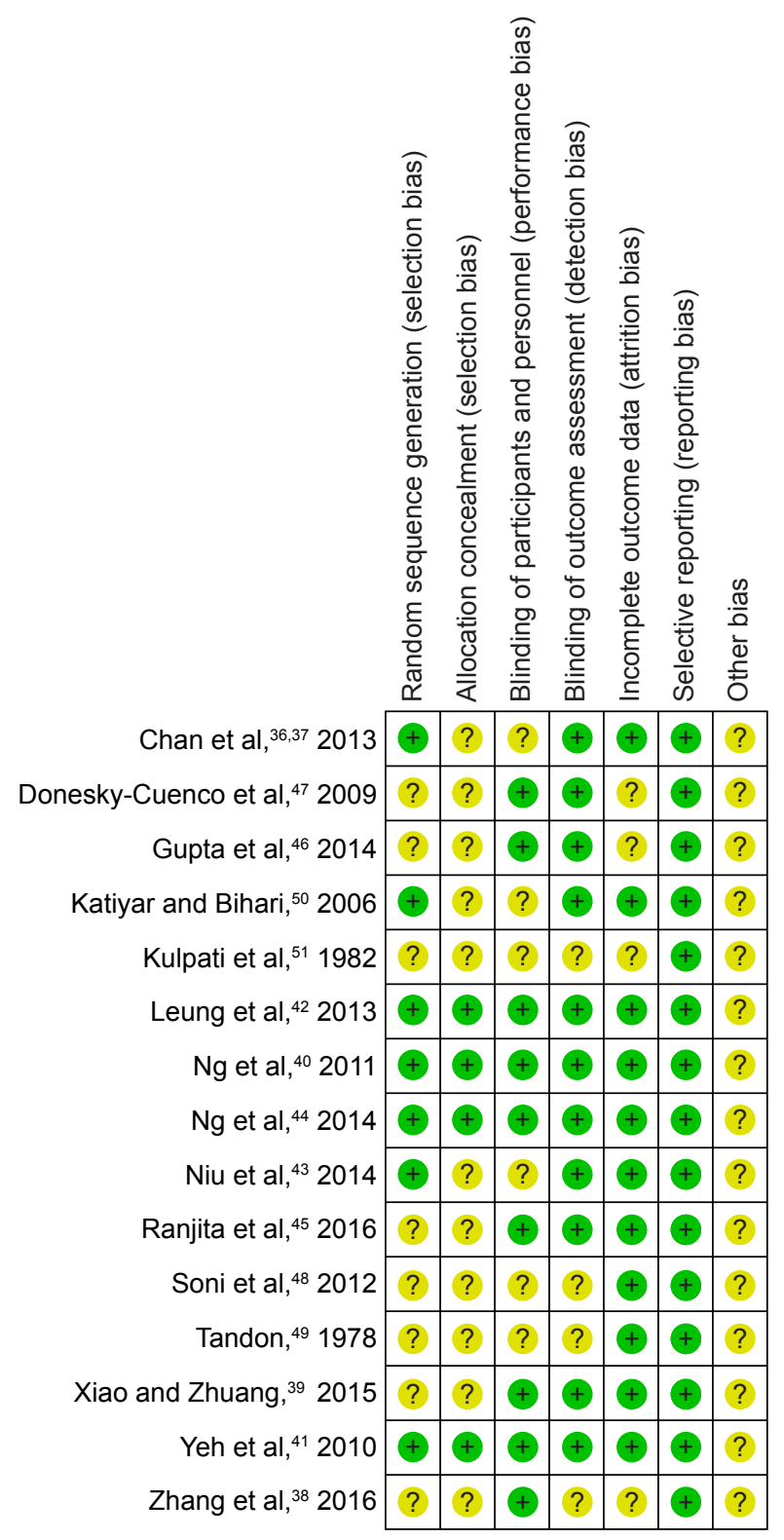

Figure 2 Risk of bias summary.

to $29.72, P<0.0002)$. The test for heterogeneity was significant $\left(P\right.$ for heterogeneity $=0.0006, I^{2}=83 \%$; Figure $\left.3 \mathrm{~B}\right)$.

\section{Lung functions}

FEV

Meditative movement versus nonexercise

Trough $\mathrm{FEV}_{1}$ data were available in 4 trials $^{36,38,44,50}$ and in 4 trials $^{36,38,43,44}$ at 3 months and 6 months $(n=489$ and $n=453$, respectively). The differences were significant (MD 0.1L, $95 \%$ CI: 0.02 to $0.18, P=0.02$ ) at 3 months. However, the aggregate results of these studies indicated that the experimental group was in related with a significant improvement in $\mathrm{FEV}_{1}$ comparing with the nonexercise group (MD $0.18 \mathrm{~L}$,
95\% CI: 0.1 to $0.26, P<0.00001)$ at 6 months. Class differences did not appear significantly different at 3 and 6 months (Figure 4A).

\section{Meditative movement versus walking exercise}

In a pooled analysis of 2 studies $(n=226)^{36,38}$ of experimental versus physical exercise groups, no significant difference was shown in $\mathrm{FEV}_{1}$ (MD 0.13L, 95\% CI: -1.04 to 0.31, $P=0.13$ ) using a random-effects model at 3 months. For $\mathrm{FEV}_{1}$, the significant interaction effect of time by group ( $P$ for heterogeneity=0.14, $I^{2}=54 \%$ ) was also observed. Again, no obvious improvement was seen at 6 months (MD $0.26 \mathrm{~L}, 95 \% \mathrm{CI}:-0.12$ to $0.64, P=0.18)$. The results of the heterogeneity test was significant $(P$ for heterogeneity $=0.001$, $I^{2}=91 \%$; Figure 4B).

\section{FEV , percent predicted normal values}

Four studies ${ }^{38,46,47,51}$ on 211 participants examined the effects of experimental group versus nonexercise on dyspnea at 3 months, using $\mathrm{FEV}_{1} \%$ predicted normal values. Regarding lung function, the experimental group statistically increased FEV $_{1}$ (MD 4L, 95\% CI: 2.7 to 5.31, $P<0.00001, P$ for heterogeneity $=0.69, I^{2}=0 \%$ ). However, there was a trend in favor of experimental group after 24 weeks (n=279, MD 4.8L, $95 \%$ CI: 2.56 to $7.07, P<0.00001)$. There was no statistically significant difference in $\mathrm{FEV}_{1}$ pre\% between groups ( $P$ for heterogeneity $=0.60, I^{2}=0 \%$ ), as shown in Figure 5 .

\section{Quality of life}

\section{Meditative movement versus nonexercise}

Two studies ${ }^{41,42}$ used Chronic Respiratory Disease Questionnaire (CRQ) to evaluate changes in quality of life, with only 24 participants each in both the experimental group and the control group at 3 months. The MD in total score was 1.92 units ( $95 \%$ CI: $0.54-3.31, P$-value $=0.006)$. As to component scores, there were not statistically significant difference in mastery ( $95 \% \mathrm{CI}:-0.49-3.62, P$-value $=0.14)$ and emotion (95\% CI: $-0.11-2.41, P$-value $=0.07)$ between groups. No significant differences in dyspnea and fatigue were also observed between groups (MD 0.9 units, 95\% CI: $0.51-1.29, P<0.00001$; MD 0.75 units, $95 \%$ CI: $0.42-1.09$, $P<0.0001$, respectively). However, the 2 component scores were highly heterogeneous, as one favored the emotion subscores ( $P$ for heterogeneity $=0.03, I^{2}=78 \%$ ) and the other the mastery subscores $\left(P\right.$ for heterogeneity $<0.00001, I^{2}=96 \%$; Figure 6). Furthermore, CRQ scores at 3 months were only captured in 2 studies $(n=24)$; therefore, the end point was 
A

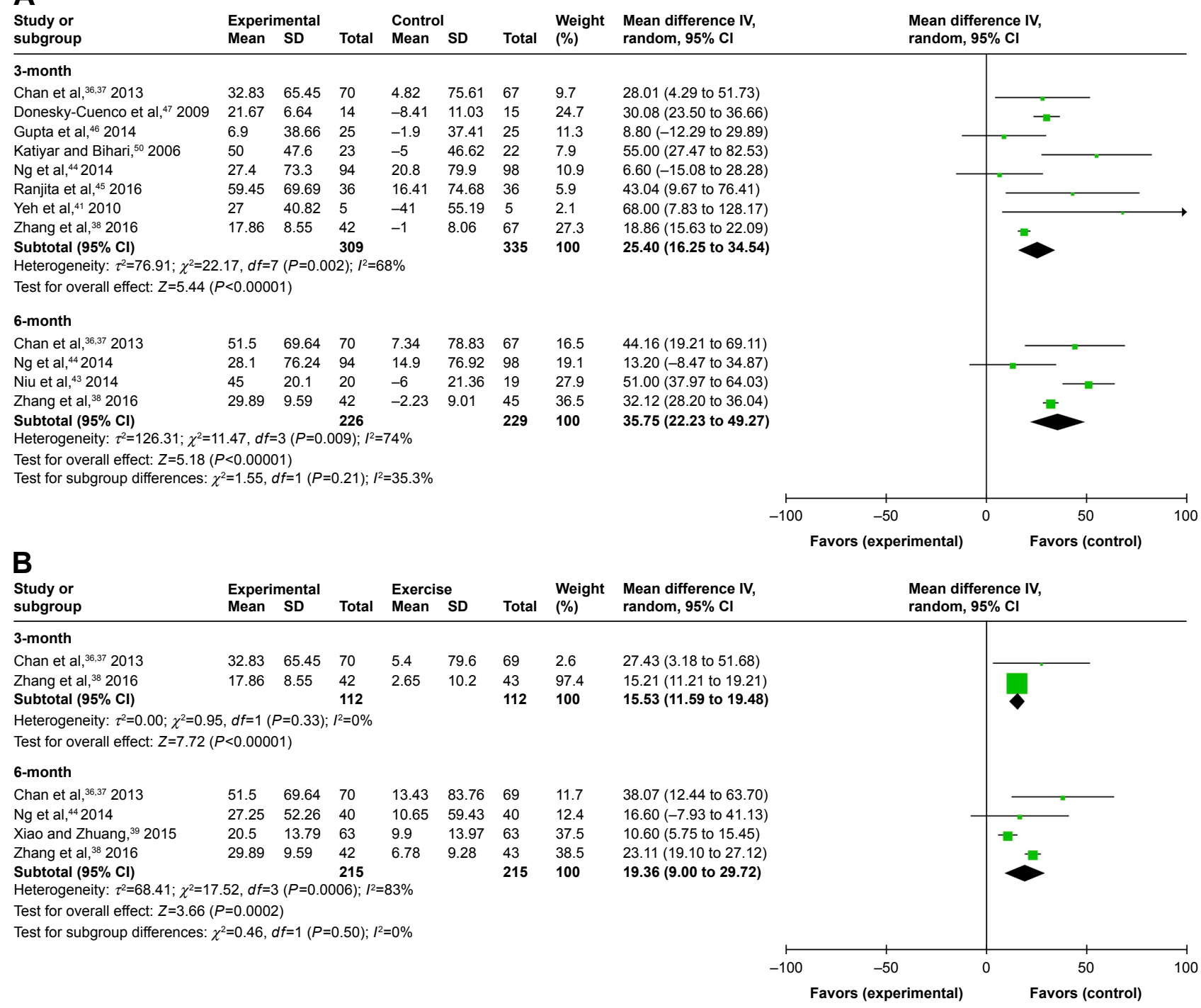

Figure 3 (A) Forest plot of comparison: meditative movement versus nonexercise, outcome: 6-minute walk test. (B) Forest plot of comparison: meditative movement versus walking exercise, outcome: 6-minute walk test.

evaluated in a comparatively smaller population. Heterogeneity was also relatively high between the 2 trials comprising the third month end point.

\section{Meditative movement versus walking exercise}

HRQoL was evaluated by CRQ in 2 studies $^{39,40}$ at 6 months. The experimental group showed a significantly decreased fatigue subscores (MD 0.2 units, 95\% CI: 0.12 to 0.28 , $P<0.00001)$ compared with the exercise group. The pooled effect size showed that the experimental group had a lower CRQ score than the exercise group (dyspnea: MD 0.46 units, $95 \%$ CI: -0.28 to $1.20, P=0.23$; emotion: MD 0.04 units, $95 \%$ CI: -0.34 to $0.42, P=0.84$; mastery: MD 0.00 units, $95 \%$ CI: -0.32 to $0.33, P=0.98$ ). The improvement of dyspnea after intervention was reported in another trial using the fatigue section of CRQ, but the difference was not significant (Figure 7). However, heterogeneity was high for the other end points.

\section{Discussion}

According to the results of the present review, the pooled effect sizes indicated that meditative movement might be more beneficial to improving lung function of people with COPD than nonexercise. A pooled effect from 2 trials shows that meditative movement was more beneficial to reducing dyspnea and fatigue in COPD patients than nonexercise after 3 months. This study aims to evaluate the effects of meditative movement across multiple COPD populations. The current meta-analysis is distinct from previous reviews in several aspects. Our meta-analysis identified and included 
A

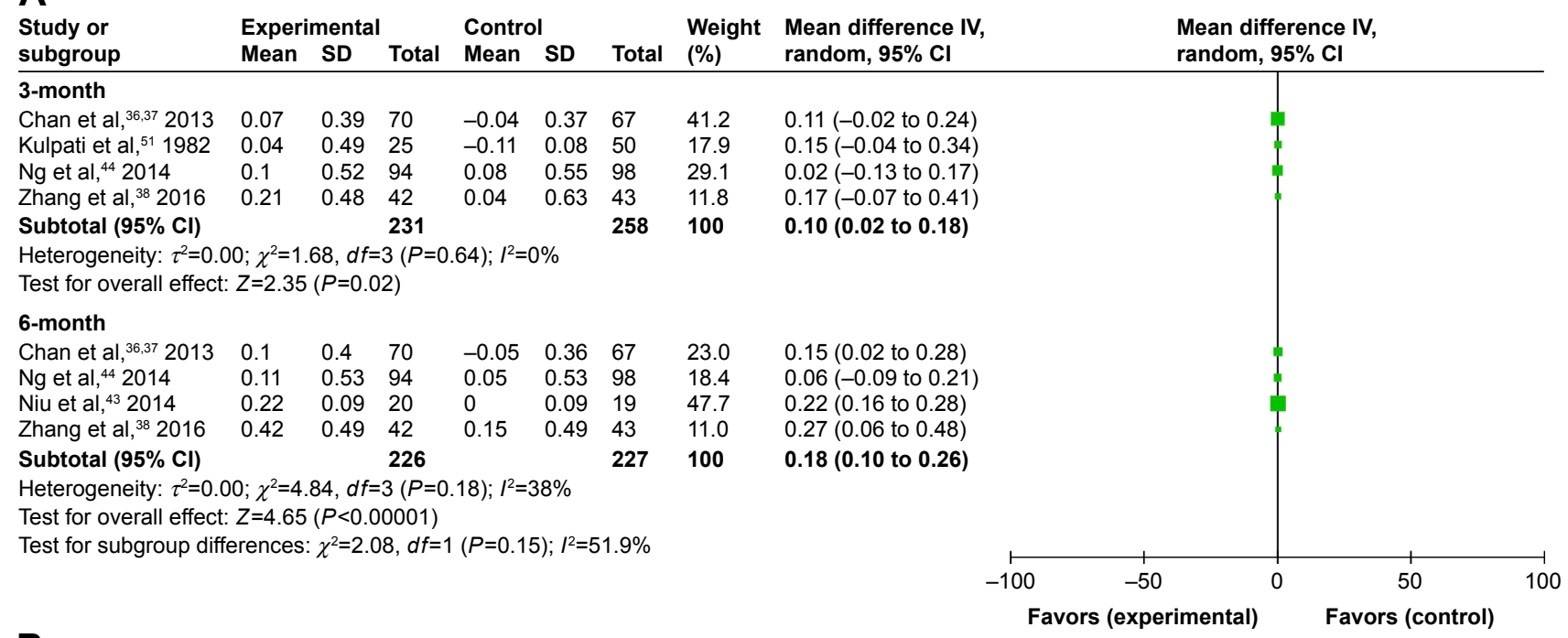

B

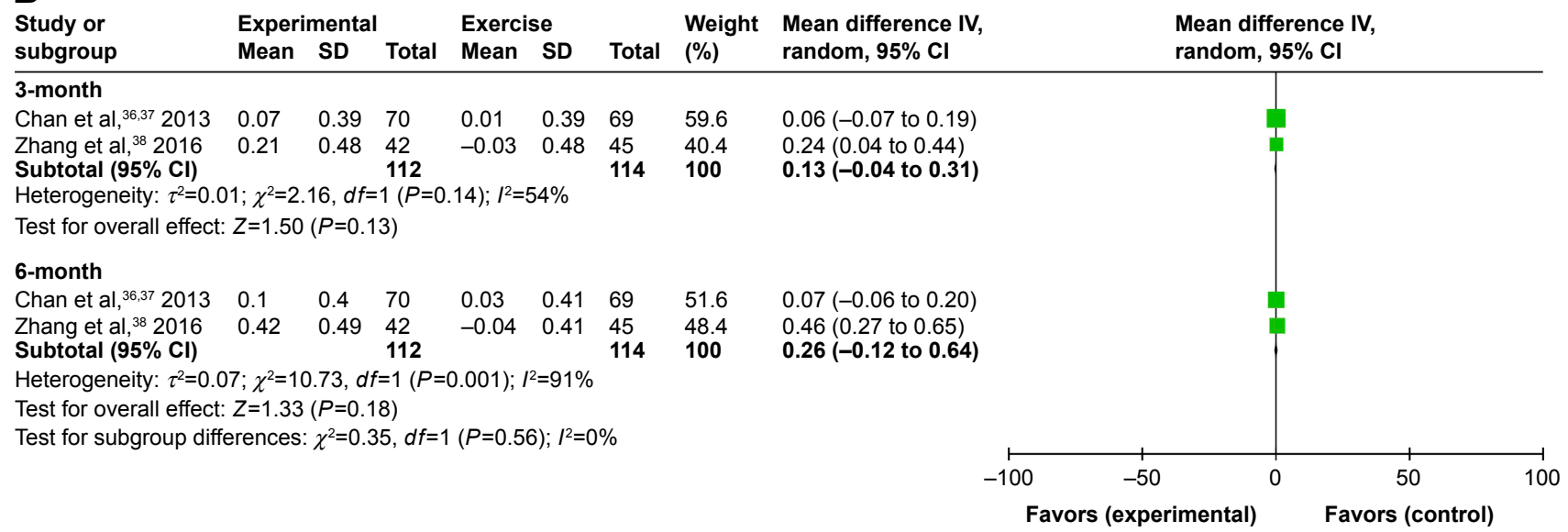

Figure 4 (A) Forest plot of comparison: meditative movement versus nonexercise, outcome: forced expiratory volume in I s. (B) Forest plot of comparison: meditative movement versus walking exercise, outcome: forced expiratory volume in I s.

more eligible studies than the previous reviews. Progressive decline in physical condition of COPD patients reduces their ability to perform daily physical activity. Our results aimed to evaluate the effectiveness of experimental programs in enhancing rehabilitation of COPD patients. The efficacy and safety of meditative movement have been evaluated in previous studies. A pulmonary rehabilitation index, comprising exercise capacity, lung function, and HRQoL, was measured

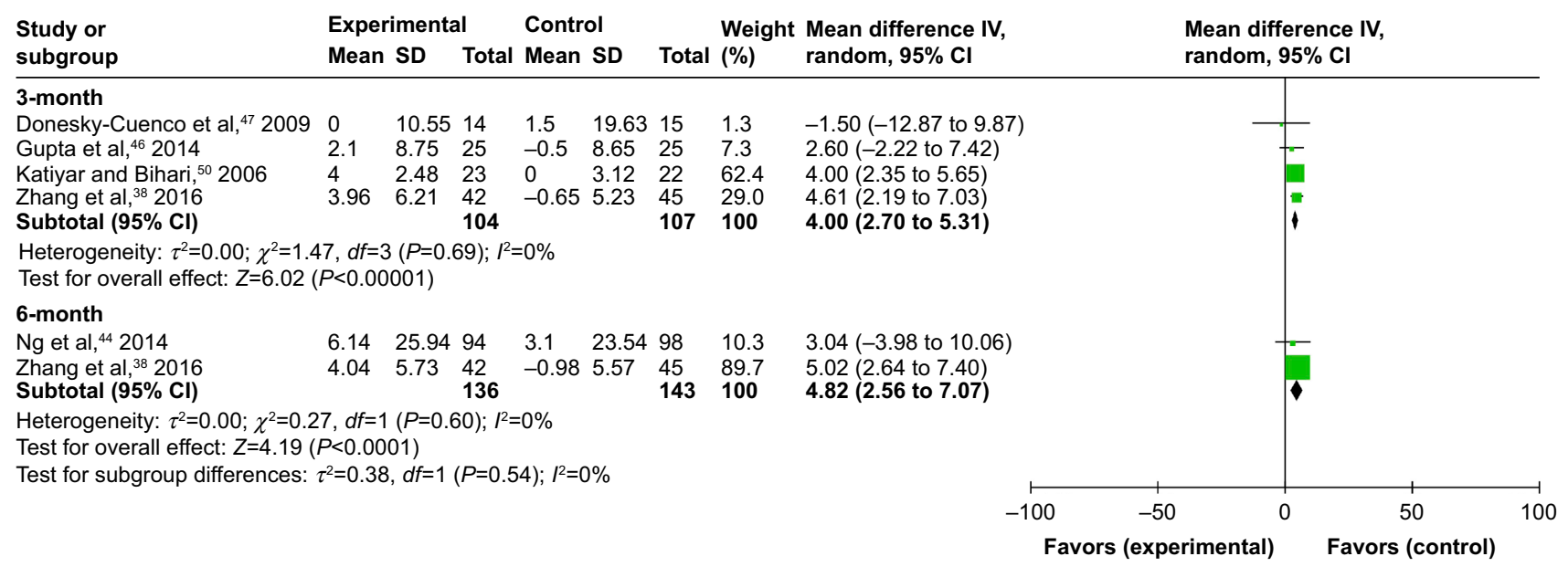

Figure 5 Forest plot of comparison: meditative movement versus nonexercise, outcome: FEV, percent predicted normal values.

Abbreviation: $\mathrm{FEV}_{1}$, forced expiratory volume in I s. 


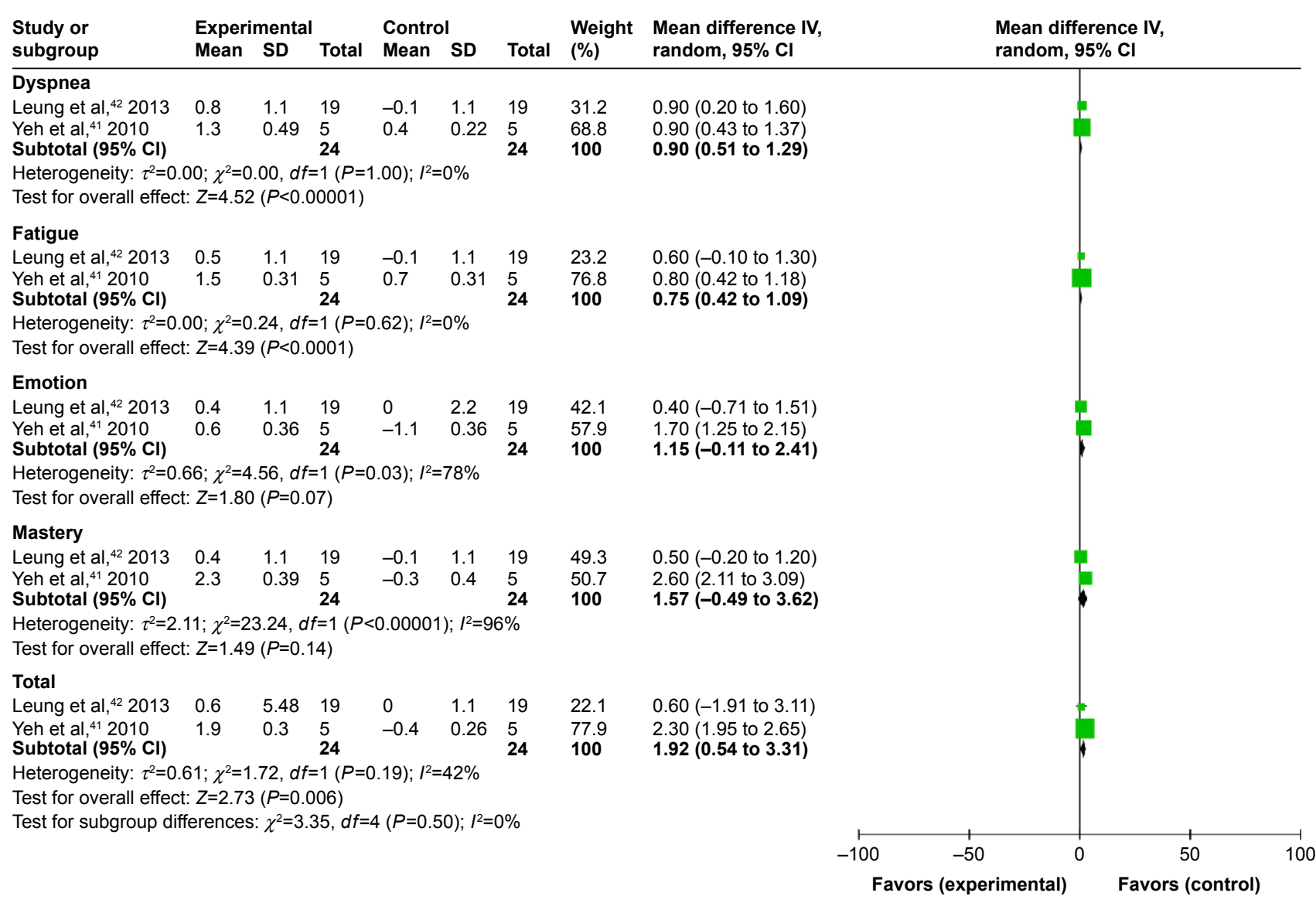

Figure 6 Forest plot of comparison: meditative movement versus nonexercise, outcome: CRQ, 3-month. Abbreviation: CRQ, Chronic Respiratory Disease Questionnaire.

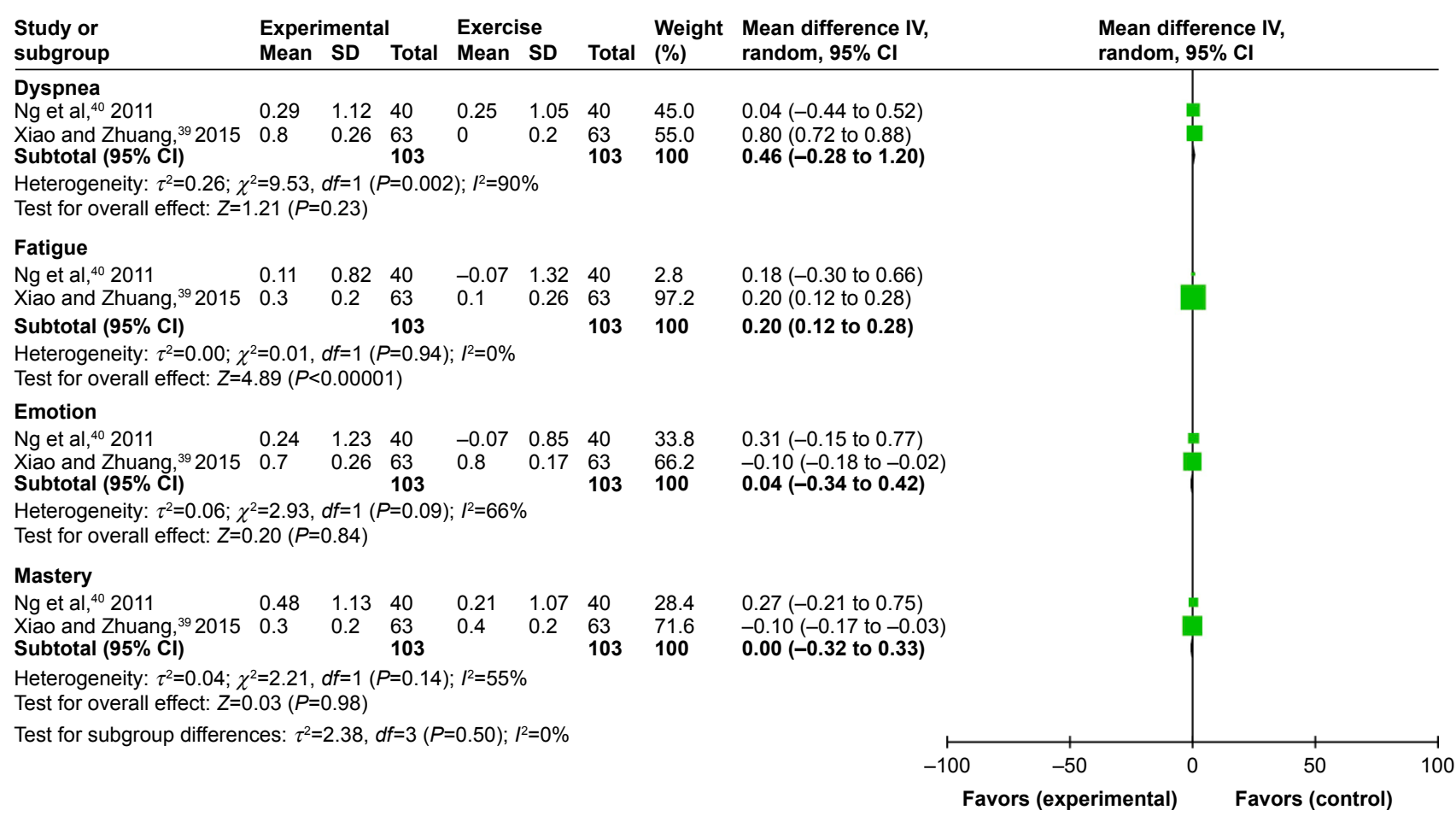

Figure 7 Forest plot of comparison: meditative movement versus walking exercise, outcome: CRQ, 6-month. Abbreviation: CRQ, Chronic Respiratory Disease Questionnaire. 
at baseline, 3 and 6 months. This review provided evidence of the effectiveness of meditative movement toward improving the exercise capacity. This study evaluates the effect of meditative movement across multiple COPD populations. This review provided evidence on the effectiveness of meditative movement in improving the exercise capacity, pulmonary function, and quality of life of COPD patients, as long as participants adhered to the protocol. Subjects in the experimental group required considerable practice to attain proficiency. Tai chi qigong (TCQ) is a low-intensity, rhythmic circular exercise incorporating musculoskeletal, respiration, and meditation training. ${ }^{17,18}$ The movements are coordinated with deep breathing that draws the breath down into the lower tantien (the main energy center of the body). TCQ might enhance the lung capacity and diaphragm strength, and improve cardiorespiratory function. ${ }^{17}$ Yoga exerted beneficial effects by reducing breathing frequency, modulating airway reactivity, ${ }^{19}$ increasing respiratory sensation through conditioning of the breathing pattern, ${ }^{20}$ reducing oxygen consumption, ${ }^{21}$ decreasing responses to hypoxic and hypercapnic conditios ${ }^{22}$ with better blood oxygenation without increasing minute ventilation, ${ }^{23}$ improving respiratory muscle strength and endurance at least for a shortterm, ${ }^{24}$ and decreasing the resting heart rate and sympathetic reactivity. ${ }^{25}$

In recent decades, 6MWD has been used as a simple and valid evaluation parameter for exercise tolerance of COPD patients. ${ }^{26-28}$ In our study, statistically significant increase in 6MWD was noted among participants allocated to meditative movement compared with those allocated to the nonexercise group. However, no significant difference was found in walking distance between the meditative movement and the walking exercise groups. This might be owing to the walking in the exercise group being self-paced instead of maximal shuttle walking, and most participants not gaining maximal exercise capacity during walking exercise unless closely monitored. ${ }^{29}$ The result was similar to previous studies showing rehabilitation at home showed no objective improvement in exercise capacity among COPD patients. ${ }^{30,31}$ The follow-up durations of meditative movement training in our studies ranged from 6 weeks to 9 months, the loss of lung function due to pathophysiological process of COPD might not be demonstrable in such short follow-up duration. Therefore, it remained unclear whether improvements gained in lung function owing to the treatment duration using meditative movement can be maintained in the longer term. Hence, the duration of meditative movement and assessment periods should be longer. Studies did not reveal any definitive conclusions regarding the effective "dose" of meditative movement, or whether tai chi, yoga, or qigong were more effective. Future studies should pay attention to optimizing training intensity, duration, and frequency of meditative movement.

Previous studies have revealed that positive effects of pulmonary rehabilitation on HRQoL were achieved during hospitalization. However, the effects decreased and could not be sustained after discharge..$^{32,33}$ This study adopted the CRQ to evaluate HRQoL. Meditative movement might regulate more effective emotion to elicit much higher levels of general self-efficacy belief. ${ }^{34}$ Emotional self-efficacy belief may improve individual subjective happiness, interpersonal relationships, and ability to build up a positive attitude toward diseases. ${ }^{35}$ Participants can cherish feelings of concern and love from others through communicating and propagating health education. The results support the hypothesis that meditative movement appeared to be more beneficial than pulmonary rehabilitation incorporating the popular breathing and walking exercises in patients with COPD. However, firm conclusion could not be drawn owing to the small sample size.

Several limitations have to be mentioned regarding our systematic review and meta-analysis. First, there were heterogeneities in the inclusion the populations studied, the diverse style of meditative movement, time points when interventions was initiated, intensity, duration, and study quality. These factors were not comparable in most of the trials. These differences may explain the statistical heterogeneity that existed in some of the outcomes investigated. The duration of meditative movement observed included studies that were not too long enough to evaluate the longterm effects, and the optimal exercise intensity and duration currently remains unknown. Second, although we tried to pool results of all the trials, the number of patients included in this meta-analysis might not be sufficient to exclude any significant clinical benefits. Third, the quality of the included studies were not consistent, which could affect the direction and magnitude of treatment effects when performing a meta-analysis. Especially, the poor-quality trials that consistently reported active results of the outcomes. Fourth, some important physiological outcome measures, such as inflammatory biomarkers, and peripheral and respiratory muscle strength and functions were lacking in most studies. Moreover, despite multiple outcome measures being used, it is not always possible to interpret the effect against a minimal clinically important difference for each measure. Finally, since most trials were conducted in Southeast Asia, caution 
should be taken regarding the generalization of results for the European population. It is possible that the willingness to participate in meditative movement training is impacted by national and ethnic cultures.

\section{Conclusion}

The current systematic review and meta-analysis revealed that meditative movement might improve exercise capacity, dyspnea, HRQoL, and lung function in COPD patients. So, meditative movement should be encouraged as a potential and crucial approach to COPD. However, considering the limitations of our study, questions remain to be evaluated in large-scale, well-designed, multicenter, RCTs to substantiate the preliminary findings and investigate the long-term effects of meditative movement as well as the tailoring of the rehabilitation intervention for COPD patients.

\section{Disclosure}

The authors report no conflicts of interest in this work.

\section{References}

1. World Health Organization. World Health Statistics. Online document at: Available from: http://www.who.int/gho/publications/world_health_ statistics/en/. Accessed November 24, 2009.

2. Zhong N, Wang C, Yao W, et al. Prevalence of chronic obstructive pulmonary disease in China: a large, population-based survey. Am J Respir Crit Care Med. 2007;176(8):753-760.

3. Vestbo J, Hurd SS, Agustí AG, et al. Global strategy for the diagnosis, management, and prevention of chronic obstructive pulmonary disease: GOLD executive summary. Am J Respir Crit Care Med. 2013;187(4): 347-365.

4. Seemungal TA, Donaldson GC, Paul EA, Bestall JC, Jeffries DJ, Wedzicha JA. Effect of exacerbation on quality of life in patients with chronic obstructive pulmonary disease. Am J Respir Crit Care Med. 1998;157(5 Pt 1):1418-1422.

5. Divo M, Pinto-Plata V. Role of exercise in testing and in therapy of COPD. Med Clin North Am. 2012;96(4):753-766.

6. Singh S, Harrison S, Houchen L, Wagg K. Exercise assessment and training in pulmonary rehabilitation for patients with COPD. Eur J Phys Rehabil Med. 2011;47(3):483-497.

7. Fabbri LM, Hurd SS; GOLD Scientific Committee. Global strategy for the diagnosis, management and prevention of COPD: 2003 update. Eur Respir J. 2003;22(1):1-2.

8. Nici L, Donner C, Wouters E, et al; ATS/ERS Pulmonary Rehabilitation Writing Committee. American Thoracic Society/European Respiratory Society statement on pulmonary rehabilitation. Am J Respir Crit Care Med. 2006;173(12):1390-1413.

9. Larkey L, Jahnke R, Etnier J, Gonzalez J. Meditative movement as a category of exercise: implications for research. $J$ Phys Act Health. 2009;6(2):230-238.

10. Garripoli G. Qigong: Essence of the Healing Dance. FL, USA: Health Communications; 1999.

11. Fulambarker A, Farooki B, Kheir F, Copur AS, Srinivasan L, Schultz S. Effect of yoga in chronic obstructive pulmonary disease. Am J Ther 2012;19(2):96-100.

12. Norweg A, Collins EG. Evidence for cognitive-behavioral strategies improving dyspnea and related distress in COPD. Int J Chron Obstruct Pulmon Dis. 2013;8:439-451.
13. Pomidori L, Campigotto F, Amatya TM, Bernardi L, Cogo A, et al. Efficacy and tolerability of yoga breathing in patients with chronic obstructive pulmonary disease: a pilot study. J Cardiopulm Rehabil Prev. 2009;29(2):133-137.

14. Higgins JP, Green S, editors. Cochrane Handbook for Systematic Reviews of Interventions Version 5.1.0. Oxford: The Cochrane Collaboration; 2011. Updated March 2011. Available from: http://www. cochrane-handbook.org. Accessed 20 March 2011.

15. Borenstein M, Hedges LV, Higgins JPT, Rothstein HR. Introduction to Meta-Analysis. Chichester, West Sussex: John Wiley \& Sons, Ltd; 2009.

16. Higgins JP, Thompson SG, Deeks JJ, Altman DG. Measuring inconsistency in meta-analyses. BMJ. 2003;327(7414):557-560.

17. Li JX, Hong Y, Chan KM. Tai Chi: physiological characteristics and beneficial effects on health. Br J Sport Med. 2001;35(3): $148-156$.

18. Chen KM, Snyder M, Krichbaum K. Clinical use of tai chi in elderly populations. Geriatric Nurs. 2001;22(4):198-200.

19. Singh V, Wisniewski A, Britton J, Tattersfield A. Effect of yoga breathing exercises (pranayama) on airway reactivity in subjects with asthma. Lancet. 1990;335(8702):1381-1383.

20. Villien F, Yu M, Barthélémy P, Jammes Y. Training to yoga respiration selectively increases respiratory sensation in healthy man. Respir Physiol Neurobiol. 2005;146(1):85-96.

21. Telles S, Reddy SK, Nagendra HR. Oxygen consumption and respiration following two yoga relaxation techniques. Appl Psychophysiol Biofeedback. 2000;25(4):221-227.

22. Bemardi L, Spicuzza L, Portal C, et al. Yoga and chemoreflex sensitivity. Lancet. 2001;357:807.

23. Bernardi L, Passino C, Wilmerding V, et al. Breathing patterns and cardiovascular autonomic modulation during hypoxia induced by simulated altitude. J Hypertens. 2001;19(5):947-958.

24. Madanmohan, Thombre DP, Balakumar B, et al. Effect of yoga training on reaction time, respiratory endurance and muscle strength Ind J Physiol Pharmacol. 1992;36(4):229-233.

25. Khanam AA, Sachdeva U, Guleria R, Deepak KK. Study of pulmonary and autonomic functions of asthma patients after yoga training. Indian J Physiol Pharmacol. 1996;40(4):318-324.

26. Butland RJ, Pang J, Gross ER, Woodcock AA, Geddes DM. Two-, six-, and 12-minute walking tests in respiratory disease. Br Med J (Clin Res Ed). 1982;284(6329):1607-1608.

27. Poulain M, Durand F, Palomba B, et al. 6-minute walk testing is more sensitive than maximal incremental cycle testing for detecting oxygen desaturation in patients with COPD. Chest. 2003;123(5): 1401-1407.

28. Chen H, Liang BM, Tang YJ, et al. Relationship between 6-minute walk test and pulmonary function test in stable chronic obstructive pulmonary disease with different severities. Chin Med J (Engl). 2012;125(17): 3053-3058.

29. ATS Committee on Proficiency Standards for Clinical Pulmonary Function Laboratories. ATS statement: guidelines for the six-minute walk test. Am J Respir Crit Care Med. 2002;166(1):111-117.

30. Puente-Maestu L, Luisa Sánz M, Sánz P, de Oña RJ, Arnedillo A, Casaburi R. Long-term effects of a maintenance program after supervised or self-monitored training programs in patients with COPD. Lung. 2003;181(2):67-78

31. Wijkstra PJ, Van Altena R, Kraan J, Otten V, Postma DS, Koëter GH. Quality of life in patients with chronic obstructive pulmonary disease improves after rehabilitation at home. Eur Respir J. 1994;7(2): 269-273.

32. Green RH, Singh SJ, Williams J, Morgan MD. A randomised controlled trial of four weeks versus seven weeks of pulmonary rehabilitation in chronic obstructive pulmonary disease. Thorax. 2001;56(2): 143-145.

33. Ketelaars CA, Abu-Saad HH, Schlösser MA, Mostert R, Wouters EF. Long-term outcome of pulmonary rehabilitation in patients with COPD Chest. 1997;112(2):363-369. 
34. Yu Y, Peng L, Tang T, Chen L, Li M, Wang T. Effects of emotion regulation and general self-efficacy on posttraumatic growth in Chinese cancer survivors: assessing the mediating effect of positive affect. Psychooncology. 2014;23(4):473-478.

35. Chamanabad AG, Mirdoraghi F, Pakmehr H. The relationship of M.A. students'metacognitive and selfefficacy belief with their mental health. Procedia Soc Behav Sci. 2011;15:3050-3055.

36. Chan AW, Lee A, Lee DT, et al. The sustaining effects of Tai chi Qigong on physiological health for COPD patients: a randomized controlled trial. Complement Ther Med. 2013;21(6):585-594.

37. Chan AW, Lee A, Lee DT, Sit JW, Chair SY. Evaluation of the sustaining effects of Tai Chi Qigong in the sixth month in promoting psychosocial health in COPD patients: a single-blind, randomized controlled trial. Sci World J. 2013;2013:425082.

38. Zhang M, Xv G, Luo C, Meng D, Ji Y. Qigong Yi Jinjing promotes pulmonary function, physical activity, quality of life and emotion regulation self-efficacy in patients with chronic obstructive pulmonary disease: a Pilot Study. J Altern Complement Med. 2016;22(10):810-817.

39. Xiao CM, Zhuang YC. Efficacy of Liuzijue Qigong in individuals with chronic obstructive pulmonary disease in remission. J Am Geriatr Soc. 2015;63(7):1420-1425.

40. Ng BH, Tsang HW, Jones AY, So CT, Mok TY. Functional and psychosocial effects of health qigong in patients with COPD: a randomized controlled trial. J Altern Complement Med. 2011;17(3):243-251.

41. Yeh GY, Roberts DH, Wayne PM, Davis RB, Quilty MT, Phillips RS. Tai chi exercise for patients with chronic obstructive pulmonary disease: a pilot study. Respir Care. 2010;55(11):1475-1482.

42. Leung RW, McKeough ZJ, Peters MJ, Alison JA. Short-form Sun-style t'ai chi as an exercise training modality in people with COPD. Eur Respir J. 2013;41(5):1051-1057.

43. Niu R, He R, Luo BL, Hu C. The effect of tai chi on chronic obstructive pulmonary disease: a pilot randomised study of lung function, exercise capacity and diaphragm strength. Heart Lung Circ. 2014;23(4): $347-352$.
44. Ng L, Chiang LK, Tang R, et al. Effectiveness of incorporating Tai Chi in a pulmonary rehabilitation program for chronic obstructive pulmonary disease (COPD) in primary care - a pilot randomized controlled trial. Eur J Integr Med. 2014;6(3):248-258.

45. Ranjita R, Hankey A, Nagendra HR, Mohanty S. Yoga-based pulmonary rehabilitation for the management of dyspnea in coal miners with chronic obstructive pulmonary disease: a randomized controlled trial. J Ayurveda Integr Med. 2016;7(3):158-166.

46. Gupta A, Gupta R, Sood S, Arkham M. Pranayam for treatment of chronic obstructive pulmonary disease: results from a randomized, controlled trial. Integr Med (Encinitas). 2014;13(1):26-31.

47. Donesky-Cuenco D, Nguyen HQ, Paul S, Carrieri-Kohlman V. Yoga therapy decreases dyspnea-related distress and improves functional performance in people with chronic obstructive pulmonary disease: a pilot study. J Altern Complement Med. 2009;15(3):225-234.

48. Soni R, Munish K, Singh K, Singh S. Study of the effect of yoga training on diffusion capacity in chronic obstructive pulmonary disease patients: a controlled trial. Int J Yoga. 2012;5(2):123-127.

49. Tandon MK. Adjunct treatment with yoga in chronic severe airways obstruction. Thorax. 1978;33(4):514-517.

50. Katiyar SK, Bihari S. Role of pranayama in rehabilitation of COPD patients - a randomized controlled study. Indian J Allergy Asthma Immunol. 2006;20(2):98-104.

51. Kulpati DD, Kamath RK, Chauhan MR. The influence of physical conditioning by yogasanas and breathing exercises in patients of chronic obstruction pulmonary disease. J Assoc Physicians India. 1982;30: 865-868.

52. Chan AW, Lee A, Suen LK, Tam WW. Effectiveness of a Tai chi Qigong program in promoting health-related quality of life and perceived social support in chronic obstructive pulmonary disease clients. Qual Life Res. 2010;19(5):653-664.

53. Chan AW, Lee A, Suen LK, Tam WW. Tai chi Qigong improves lung functions and activity tolerance in COPD clients: a single blind, randomized controlled trial. Complement Ther Med. 2011;19(1):3-11.
International Journal of COPD

\section{Publish your work in this journal}

The International Journal of COPD is an international, peer-reviewed journal of therapeutics and pharmacology focusing on concise rapid reporting of clinical studies and reviews in COPD. Special focus is given to the pathophysiological processes underlying the disease, intervention programs, patient focused education, and self management protocols.

\section{Dovepress}

This journal is indexed on PubMed Central, MedLine and CAS. The manuscript management system is completely online and includes a very quick and fair peer-review system, which is all easy to use. Visit http://www.dovepress.com/testimonials.php to read real quotes from published authors. 